\title{
Contradições surgidas no Conselho Gestor da Unidade Básica de Saúde da Família de Vargem Grande, Município de Teresópolis-RJ
}

\author{
CARLOS LUIZ DA SILVA PESTANA * \\ LILIANA ANGEL VARGAS • \\ FÁTIMA TERESINHA SCARPARO CUNHA •
}

RESUMO

Este artigo apresenta o estudo das contradições surgidas no Conselho Gestor da Unidade Básica de Saúde da Família de Vargem Grande, Município de Teresópolis-RJ, na resolução das demandas da comunidade. O estudo justificase pela necessidade de se entender a micropolítica do controle público de um conselho gestor de uma unidade de Saúde da Família, cuja estratégia é a mudança do modelo de assistência a partir da Rede Básica de Saúde. Objetiva analisar a atuação desse Conselho na resolução dos impasses e problemas daquela comunidade e discutir as contradições surgidas no processo de tomada de decisões. Optou-se por um estudo de caso com abordagem qualitativa. Os sujeitos da pesquisa foram os conselheiros do CG. A coleta de dados foi realizada através da análise das atas do CG e das entrevistas realizadas com conselheiros. Utilizou-se da análise temática para identificar os impasses, problemas e contradições do CG. As análises dos dados apontam que os impasses e problemas são de ordem política, econômica, social e cultural que transcendem a resolução pelo CG. Percebe-se que as atribuições previstas para o CG revelam uma prática de controle restrita à racionalização do serviço através do gerenciamento administrativo da unidade. O CG não conseguiu interferir na política de saúde e na destinação da verba pública. Portanto, os conselheiros exercem atribuições que estão desprovidas de sentido político em garantir o pleno exercício de cidadania e a conquista dos direitos sociais. Conclui-se que o Conselho Gestor de Vargem Grande não representa ainda uma possibilidade efetiva de participação popular no controle público de um Estado ampliado no sentido gramsciano.

Palavras-chave: Conselho gestor; saúde da família; controle público.

Recebido em: 02/05/2007.

Aprovado em: 08/07/2007. 


\section{Introdução}

A Constituição Federal de 1988 e a Lei Orgânica da Saúde nº 8.142/90 definem o arcabouço jurídico-legal e expressam a ideologia da participação comunitária no Sistema Único de Saúde (SUS). Passar da teoria à prática exige um longo processo de construção que está expresso nas conferências de saúde e nos conselhos de saúde nas três esferas de governo. Constata-se ainda o surgimento de conselhos regionais, locais e gestores de unidades de saúde.

A opção de elegermos para estudo o conselho gestor de uma unidade de Saúde da Família se deve ao fato de ser a instância de participação e de decisão que está mais próxima dos usuários do SUS onde é discutido e decidido o dia-a-dia dos serviços ali demandados. Portanto, em princípio, deve oportunizar a participação dos segmentos organizados da comunidade na definição e operacionalização da política de saúde a nível local.

Gohn (2003, p. 35) salienta que "o poder local é sinônimo de força social organizada como forma de participação da população, na direção do que tem sido denominado 'empowerment' ou 'empoderamento' da comunidade". Desta forma, não se tem apenas a possibilidade de democratizar as decisões, mas a oportunidade concreta de fazer com que as reais necessidades da população sejam atendidas.

Em princípio a Saúde da Família é a estratégia de reorientação do modelo assistencial a partir da atenção básica, representando uma concepção de atenção focada no indivíduo, na família e na comunidade, que deve permitir de forma mais justa e solidária a participação comunitária, no intuito de garantir, em toda sua dimensão, o direito à saúde.

O conselho gestor na unidade de Saúde da Famíliaé um espaço que comporta grupos organizados da comunidade e do Estado e que propicia o debate, face a face, dos problemas coletivos. Neste sentido, procura-se democratizar as Unidades da Saúde da Família tendo como base o acesso às informações e a oportunidade de participação na construção do modelo de atenção à saúde proposta pelo SUS.

Carvalho (1995, p. 9) assinala que "o termo controle social tem sido usado por diversos autores da sociologia clássica para designar os processos de influência da sociedade (ou do coletivo) sobre o indivíduo", ou seja, o controle do Estado sobre a sociedade.

Prefaciando $O$ duplo sentido do controle social: (des)caminho da participação em saúde, de Wendhausen (2002), Valla advoga que o termo usado 
pela professora Amélia Cohn, da Universidade de São Paulo, de "controle público", deveria substituir o de "controle social". A justificativa para essa mudança parte da constatação de que a correlação de forças que existe no país é de fato, controle social, o que seria incoerente numa sociedade que é democrática. Neste sentido, o controle social é reforçado pelo poder de caráter conservador dos governos através dos meios de comunicação (VALLA, apud WENDHAUSEN, 2002).

Devem-se estimular reflexões e proposições para redimensionar as relações entre Estado e a sociedade, particularmente para favorecer a ampla maioria dos que se encontram excluídos dos benefícios da riqueza e do bem-estar (VALLA, 1999). Portanto, neste estudo utilizaremos o termo controle público, ou seja, a perspectiva de a sociedade civil organizada, de caráter popular, fazer valer, no cotidiano, seu direito de cidadania. É ter o poder de influenciar as políticas públicas com o objetivo de que estas atendam a suas necessidades, exercendo sua cidadania ao tomar decisões sobre a destinação da verba pública.

Controle público tem a finalidade de pôr em prática as concepções dos segmentos da sociedade de como deve ser a sociedade brasileira (VALLA, 1998). Quanto mais a sociedade se mobiliza e se organiza, maiores serão a pressão e o resultado para que seja efetivado o Estado democrático. Desta forma, as conquistas sociais e democráticas vão-se realizando através da democracia participativa.

Em virtude do exposto, concordamos com Valla (1998, p. 9), quando define a participação popular como a instância que "compreende as múltiplas ações que diferentes forças sociais desenvolvem para influenciar as formulações, execução, fiscalização e avaliação das políticas públicas e/ou serviços básicos na área social”. Desta forma, o presente estudo procura contextualizar a participação no CG na concepção de controle público.

Este trabalho apresenta como objeto de estudo as contradições surgidas no Conselho Gestor na Unidade de Saúde da Família de Vargem Grande Município de Teresópolis, no Estado do Rio de Janeiro, na resolução das demandas da comunidade. Para o desenvolvimento da pesquisa, algumas questões emergiram, a saber: como o conselho gestor trata os problemas e os impasses apontados pela comunidade? Que contradições surgem no Conselho Gestor numa Unidade de Saúde da Família no tratamento das demandas da comunidade? Apresenta como objetivos discutir as contradições surgidas no processo de tomada de decisões do referido conselho gestor e analisar a atuação desse conselho na resolução dos impasses e problemas daquela comunidade. 


\title{
Estado ampliado em Gramsci: uma nova possibilidade
}

A noção de Estado ampliado constitui elemento importante para se compreender a importância das lutas sociais. Estado ampliado em Gramsci é uma extensão do seu campo de atuação e de seu significado simbólico, ou seja, o Estado é o somatório da sociedade civil e da sociedade política, não se resumiria aos órgãos de poder das esferas governamentais. Usar tal concepção significa sair da noção restrita de um mero espaço de poder a serviço da classe dominante. É reconhecer que os conflitos sociais e as lutas perpassam os aparelhos estatais.

Para Gramsci, a conquista dos espaços políticos dentro dos órgãos estatais é importante, assim como sua democratização. Portanto, a mudança social é um processo gradual, que deve ser precedido de transformação da sociedade civil em seus valores, práticas e desenvolvimento de contra-hegemonia sobre a ordem dominante (GOHN, 2000).

Coutinho (1981, p. 103-104) assinala:

\begin{abstract}
Gramsci diferencia o Oriente do Ocidente no sentido que as batalhas, neste último, devem ser travadas inicialmente no âmbito da sociedade civil, visando à conquista de posições e de espaços "guerra de posições", da direção político-ideológico, e de consenso dos setores majoritários da população, como condição para o acesso ao poder do Estado e sua posterior conservação.
\end{abstract}

O critério central para a decisão da crise é a iniciativa dos sujeitos políticos coletivos, a capacidade de fazer política envolvendo grandes massas na solução de seus próprios problemas, nas lutas cotidianas pela conquista do espaço e posições sem perder de vista o objetivo final de promover transformação da estrutura que ponha fim à formação econômico-social capitalista (COUTINHO, 1981, p. 103-110).

Conforme notou Carlos Nelson Coutinho (1987, p. 65), "a esfera política 'restrita' [...] cede progressivamente lugar a uma nova esfera pública 'ampliada', caracterizada pelo protagonismo político de amplas e crescentes organizações de massa". O processo de ampliação da natureza do Estado é um dos aspectos centrais do pensamento de Gramsci, expresso da seguinte forma: "O Estado já não representa apenas os interesses comuns da burguesia; ele é obrigado, pela pressão de baixo, a se abrir também para outros interesses, provenientes de diferentes classes" (COUTINHO, 1989, p. 54). Portanto, 
esse autor afirma que os direitos foram conquistas das classes subalternas que fizeram com que o Estado passasse a reconhecer suas necessidades e interesses.

As discussões gramscianas sobre o Estado apresentam-se a partir da existência de duas esferas distintas no interior do Estado ou superestrutura, quais sejam: sociedade civil e sociedade política.

Sociedade civil é o espaço onde se organizam os interesses em confronto, é o lugar onde se tornam conscientes os conflitos e as contradições. Em outros termos, a sociedade civil compreende o conjunto de relações sociais que engloba a vida cotidiana, a vida em sociedade, o emaranhado das instituições e ideologias nas quais as relações se cultivam e se organizam.

A sociedade política, no pensamento gramsciano, indica o conjunto de aparelhos através do qual a classe dominante exerce a violência. Na sociedade política (Estado em sentido estrito, ou Estado-coerção) ocorre sempre o exercício da ditadura, ou seja, da dominação baseada na coerção.

A chave do marxismo gramsciano de Estado ampliado está na relação dialética entre a sociedade civil e a sociedade política que, para ele, é o próprio Estado. Para Coutinho (1989, p. 78), "não há hegemonia, ou direção política e ideológica, sem o conjunto das organizações materiais que compõem a sociedade civil enquanto esfera do ser social". A partir desta compreensão, essas esferas podem-se tornar o terreno para o encaminhamento de uma ação transformadora ou de uma ação conservadora.

As análises gramscianas afirmam que o Estado liberal não superou sua fase econômico-corporativa, ou seja, confunde sociedade civil e sociedade política. Esta relação não se coloca e a consciência política não se desenvolve como consciência de classe.

\section{As contradições do conselho gestor}

Esta unidade temática pretende discutir as contradições surgidas no Conselho Gestor da Unidade Básica de Saúde da Família de Vargem Grande. O conflito existente é gerado por uma dissociação entre a necessidade de assistência da população e a proposta que a unidade de saúde traz baseada nos programas de saúde do governo. 
Franco e Merhy (2000, p. 115) sinalizam que "é preciso uma ação que reorganize o trabalho do médico e de outros profissionais, atuando em seus processos decisórios que ocorrem no ato mesmo da produção de saúde". Assim sendo, o processo de trabalho deve pautar-se na construção de novos valores, na solidariedade, na cidadania, na humanização da assistência e na constituição de processos coletivos. Mais importante que mudar a estrutura, deve-se modificar as referências epistemológicas, destruindo o núcleo duro de comportamentos estereotipados e estruturados (FRANCO; MERHY, 2000).

Portanto, os membros do CG, contraditoriamente, apropriaram-se do discurso dos gestores e dos profissionais de saúde sobre a estratégia Saúde da Família, mas a comunidade não, e isto tem gerado conflito. Fica evidente a armadilha da dominação ideológica que as lideranças populares caíram ao assumir o discurso do poder.

Tal fato pode implicar uma "cidadania de escassez" de uma forte dependência das entidades representativas da população face ao Estado (VALLA; STOTZ, 1994). Os autores também chamam atenção para:

O processo de institucionalização aludido implica reprodução dos procedimentos administrativos típicos da burocracia estatal, vistos como necessários para "ganhar" mais rápida e eficientemente uma fatia do "bolo" orçamentário dos governos. O outro lado da moeda, isto é, a população acaba sofrendo as conseqüências de lidar com uma entidade que é bifronte: dirige suas demandas a uma associação que é sua e depende do Estado, simultaneamente. Como o que predomina é a gestão administrativa dos bens e equipamentos coletivos, a associação passa a ser vista como um poder local do Estado, uma espécie de "miniprefeitura" por onde circulam tanto moradores como os "agentes externos", entre os quais, inevitavelmente, os "políticos" na época de eleições.

Vargem Grande é muito distante dos serviços de saúde existentes no município; logo, as pessoas querem ser atendidas na unidade de saúde, ou seja, apresentam lógica coerente com seus raciocínios, de estar doente e ser atendida pelo médico da unidade, forte expressão do modelo médico-assistencial culturalmente arraigado em nossa sociedade.

Outra contradição evidencia um misto de desânimo e medo por parte de uma conselheira representante dos usuários. Desânimo em não ter conseguido resolver determinadas demandas da comunidade e medo de confrontar-se com 
os profissionais de saúde e no futuro vir a precisar de atendimento. Revela contradições ao não compreender o direito à saúde e que essa relação supõe confronto e negociação, um complexo jogo de ações e reações.

Esta visão fragmentada faz com que a questão do processo saúde-doença seja vista, numa estreita vinculação, da perspectiva exclusiva do atendimento médico, contrapondo-se ao exercício da cidadania que objetiva promover o controle público, uma garantia constitucional de direito à saúde. O desafio do CG é encontrar uma maneira de satisfazer as necessidades de saúde da população, procurar transcender o olhar para uma dimensão mais abrangente da política, entendendo os determinantes do processo saúde-doença, bem como as intervenções mais imediatas originadas no dia-a-dia da unidade. O ponto de partida é sempre a realidade concreta, os problemas vividos por cada um e expressos a seu modo.

De fato, existe uma crise de credibilidade na sociedade brasileira. $\mathrm{O}$ descrédito nos políticos, promessas, corrupções, desvios das verbas das áreas essenciais, enfim, um descaso das autoridades que reflete, de forma contundente, no rebaixamento da qualidade de vida da população.

Para Valla e Stotz (1989, p.16), “é importante chamar a atenção que as reivindicações da população são reivindicações de direito, ou seja, as autoridades, já têm o dinheiro dos impostos da população, mas não realizam os serviços exigidos e acabam gastando os impostos em outros projetos".

Corroborando com esses autores, Sposati (1998, p. 372) revela que "a ausência da esfera pública significa utilização do fundo público, do dinheiro público, de forma casuística - em regras gerais, sem um projeto transparente e sem a presença dos interesses divergentes - ao serem tomadas às decisões".

Valla e Stotz (1991, p. 16) propõem que "a população desses bairros terá que pressionar as autoridades para realizar essas obras básicas com o dinheiro dos impostos", o que, para Offe, é "converter uma mobilização social em poder político" (OFFE, 1991, p. 883 apud Munck, 1997, p. 11). Deste modo, pode-se por em xeque a ordem imposta pelas instituições políticas. Mas, por outro lado, os conselheiros do CG referem dificuldade em mobilizar a comunidade.

Observa-se, também, que os conselheiros representantes dos usuários e dos profissionais de saúde cultivam uma dependência em relação aos conselheiros representantes do gestor. Tem-se a impressão que estes desempenham suas funções como "despachantes" do CG. Além disso, a reunião é suspensa quando os representantes dos gestores não comparecem. 
Um conselheiro representante dos usuários considera preocupante a ausência dos representantes dos gestores nas reuniões do CG. Refere que são os membros da Secretaria de Saúde quem convocam as reuniões, entretanto, o presidente do Conselho é um representante dos usuários. Os profissionais de saúde e os usuários representam $75 \%$ dos membros do CG, revelando quorum suficiente para reunir e deliberar.

Para Munck (1997, p. 10), "uma das armadilhas mais freqüente do movimento é tornar-se incorporado ao sistema político-institucional, perdendo sua capacidade de lutar por questões fundamentais". Os representantes dos usuários e dos profissionais de saúde responsabilizam os representantes do gestor, e os representantes do gestor responsabilizam os profissionais de saúde pela falta de reuniões em 2005.

As contradições do CG revelam uma "cidadania de segunda classe ou de migalhas" (STOTZ, 1994). O CG não apresenta poder de decisão na resolução das demandas da comunidade. A não-resolução das demandas é justificada pelos técnicos com discursos elaborados, próprios da dominação ideológica que paralisa a ação dos representantes da população no CG, impossibilitando-os de dar respostas mais acirradas do movimento popular, ou seja, uma situação de controle social.

\section{Considerações finais}

A Democracia é como o amor: não se pode comprar, não se pode decretar, não se pode propor. A Democracia só se pode viver e construir

Bernardo Toro

Todos os homens do mundo na medida em que se unem entre si em sociedade, trabalham, lutam $e$ melhoram a si mesmos.

Gramsci

Escolhemos os pensamentos de Toro e Gramsci por considerar que os mesmos nos animam a manter viva a chama de luta esperançosa, enraizada nos processos coletivos de construção da democracia.

O estudo das contradições do Conselho Gestor da Unidade Básica de Saúde da Família de Vargem Grande na resolução das demandas daquela comunidade conduziu a reflexões sobre controle público e participação popular 
no SUS. O controle público acontece onde há cidadania, sociedade organizada e atuação do Estado. Supõe-se, no controle público, que quem deve controlar o Estado é o usuário, o cidadão diretamente afetado pela prática dos serviços e pelas políticas implementadas.

Desta forma, para que o controle público prevaleça, há necessidade de participação popular no sentido de reivindicação da população sobre o Estado, que consiste na apropriação, pela sociedade organizada, dos meios e instrumentos de planejamento, fiscalização e análise das ações dos serviços e das políticas públicas, inclusive na destinação da verba pública (VALLA, 1994).

O território de tomada de decisões do conselho gestor (CG) é a unidade de saúde. Tem-se, então, restrição nas ações desse conselho um poder limitado, gerando nos conselheiros sentimentos de desânimo e impotência para mudar a realidade. Deste modo, os conselheiros compreenderam que não fazem parte da organicidade do poder hegemônico, ou seja, ocupam vazios de poder e apresentam limitações de crescimento. São movimentos que ascendem e caem (AROUCA, 1979 apud ESCOREL, 1998).

Esta participação restrita com poderes limitados foi um importante motivo para o esvaziamento e a não-realização das reuniões do CG no ano de 2005. Ficou evidente para os conselheiros que o processo decisório público da burocracia interna da Secretaria Municipal de Saúde de Teresópolis não acata as decisões do CG, rompendo com sua autonomia. Na realidade é controle de quem sobre quem?

Diante desse quadro contraditório, o discurso é de controle público, mas a prática é de controle social, ou seja, controle do Estado sobre a sociedade. A correlação de forças limita a influência sobre a política de saúde. Há uma partilha de poder de caráter restrito, impossibilitando sua ampliação para decisões que têm impacto significativo para a sociedade como um todo.

Neste aspecto, o que se percebe é uma suposta institucionalidade, “cidadania de escassez" (VALLA, 1994). Ou seja, implica dependência muito forte das entidades representativas da população face ao Estado, que se procura consolidar como controle do Estado sobre a população, denominado controle social. As análises dos resultados revelam que o CG dessa Unidade Básica de Saúde Família (UBSF) ainda não conquistou espaço pleno para o exercício de cidadania de sujeitos democráticos populares. 
Pode-se evidenciar que o CG conseguiu entendimentos no sentido de formar acordos, nos quais o diálogo e os confrontos potencializaram aprendizados e situações consensuais. No entanto, percebe-se a fragilidade do poder do CG em tomar determinadas decisões sobre questões referentes à política de saúde.

As atas e os depoimentos mostram que a ampliação da unidade de saúde é o maior problema enfrentado pelo CG. Percebe-se que as condições da unidade de saúde interferem no processo de trabalho dos profissionais de saúde, provocando tensões, desânimo, conflitos, precarização das condições de trabalho e contradições.

Tal fato, por um lado, mostra os limites da capacidade de ação do CG, e por outro, a necessidade de articulação com outras instâncias de controle público, tais como Conselho Municipal de Saúde, Ministério Público, demais conselhos gestores e de ações, como denúncia na imprensa, passeatas e outras formas de pressão e reivindicação.

Ao confrontarmos as atribuições previstas no documento institucional "Conhecendo o PSF" para o CG em Teresópolis com os encaminhamentos propostos para o atendimento das demandas da comunidade local, verifica-se que há coerência no sentido de controle social, mas incoerência em relação ao controle público. Portanto, o que revela é controle sobre a sociedade, uma "cidadania tutelada" [grifos do autor], uma concessão de cima, ou seja, reprodução da pobreza política das maiorias. Neste aspecto, não ocorre suficiente consciência crítica para sacudir a tutela (DEMO, 1995).

Como se vê, o poder se limita à racionalização do serviço através do gerenciamento da unidade, eminentemente administrativo, provavelmente reflexo da tradicional cultura casuística e tutelar que busca reduzir cada situação a um caso particular e na maioria das vezes, "controlar os profissionais" [grifos nossos]. Sendo assim, os conselheiros exercem atribuições que são desprovidas de um sentido político pleno de exercício de cidadania na garantia dos direitos sociais.

Observam-se também contradições em relação aos conselheiros representantes dos usuários que reproduzem a lógica da espera do Estado provedor, culturalmente arraigada em nossa população. Parcialmente explicada pela assimetria educacional entre os conselheiros, a incipiente experiência em processos participativos institucionalizados, e conseqüente constituição do CG de cima para baixo, como demanda do gestor. 
A atuação do CG revela-se muito aquém de um espaço político que põe em cena interesses da população na tomada de decisões. Para que a participação popular exerça de fato a cidadania, há necessidade de processos inovadores de gestão pública, que os sujeitos sociais possam exercer o poder político de apropriação da verba pública, sem o obscurecimento da dinâmica conflitiva que impossibilita a equalização das desigualdades do exercício de cidadania. Entretanto, constatamos a necessidade de se encontrar formas alternativas e efetivas de participação popular, no sentido de assegurar os direitos, seja através da contestação e ou pressão sobre o Estado, firmando-se como efetivo controle público.

Os representantes dos usuários trazem uma agenda pertinente de problemas, objetivos e demandas, propiciando acordos sobre a realidade da comunidade, tornando legítimas suas reivindicações junto à equipe de saúde, à Secretaria de Saúde e à Prefeitura.

O CG estudado pode ser considerado um laboratório social, com efeito multiplicador de aprendizagens, a partir das ações que realiza no nível local e que significam experiências portadoras de futuro.

Na Unidade de Saúde da Família, o CG propicia um espaço que comporta grupos organizados da comunidade e do Estado para o debate, face a face aos problemas da saúde coletiva. Pode oferecer para o poder público a visão e o interesse de parcelas da sociedade. Todavia, os espaços precisam ter poder deliberativo e a população saber exercê-lo, ou seja, não estar atrelada às decisões do gestor. $\mathrm{O}$ aperfeiçoamento se dá na prática, no cotidiano, na revelação das contradições e no exercício democrático de construção do controle público.

Romper com a prática do fisiologismo e do clientelismo é ir contra a lógica da apropriação do público pelo interesse privado. Essas práticas são instrumentos de dominação das elites e possuem raízes profundas nas desigualdades no Brasil. Entende-se, assim, que a relação complexa entre Estado e sociedade é um processo permanente de luta e transformação mútua. O percurso de implantação do modelo econômico neoliberal nos últimos 17 anos no Brasil tem deixado rastros de ampliação da pobreza e do inconseqüente desmonte do Estado.

Pode-se, assim dizer, que para o projeto neoliberal, o que vale é o mercado, portanto, seus princípios são antagônicos aos interesses sociais. Assim, o rumo no sentido de defesa das políticas sociais deve estar fortemente ligado à possibilidade de politização das necessidades reais da sociedade relacionadas com a questão da igualdade (RODRIGUES, 2003). 
De fato, o neoliberalismo é antagônico às políticas sociais universais, portanto é um processo que apresenta avanços e recuos. Porém, tal contradição se manifesta como um processo, no qual o capitalismo resiste, depois é forçado a recuar e fazer concessões, sem nunca deixar de tentar instrumentalizar a seu favor os direitos conquistados (COUTINHO, 2000).

Para finalizar, é importante dizer que mesmo com as contradições, impasses e as limitações identificadas neste estudo, as análises mostram o quão promissor é o campo do controle público e da participação popular no acompanhamento do serviço e das políticas públicas. A construção da democracia se dará através de processos de participação da sociedade na implementação das políticas públicas, ou seja, que a participação popular possa ser contra-hegemônica. Haverá sempre tensões, contradições e, como diria Gramsci, guerra de posições pela conquista de espaços (COUTINHO, 2000).

O Conselho Gestor de Vargem Grande se apresentou como uma oportunidade de gerenciamento administrativo da unidade, ou seja, o de "controlar o serviço", mas ainda não representa uma possibilidade efetiva de participação popular no controle público de um Estado ampliado no sentido gramsciano. Portanto, longe de se ter esgotado a temática, procura-se acentuar as contradições do CG, e assim, possibilitar manter viva e acesa a chama da cidadania e firmar caminhos na tarefa de prosseguir no processo de construção da sociedade que queremos.

\section{Referências}

BRASIL. Ministério da Saúde. Lei Orgânica da Saúde nº. 8.080/90. Dispõe sobre as condições para a promoção, proteção e recuperação da saúde, a organização e o funcionamento dos serviços correspondentes e dá outras providências. Diário Oficial [da] República Federativa do Brasil, Brasília, DF, v. 128, n. 182, p. 18.055-18.055, 20 set. Seção I, pt. 1.

BRASIL. Ministério da Saúde. Lei Orgânica da Saúde nº. 8.142/90. Dispõe sobre a participação da comunidade na gestão do Sistema Único de Saúde e sobre as transferências intergovernamentais de recursos financeiros na área da saúde e dá outras providências. Diário Oficial [da] República Federativa do Brasil, Brasília, DF, 31 dez. 1990. 
CARVAlHO, A. I. Conselho de Saúde no Brasil: participação cidadã e controle social. Rio de Janeiro: FASE, 1995.

COUTINHO C. N. Contra a corrente: ensaios sobre democracia e socialismo. São Paulo: Cortez, 2000.

. Fontes do pensamento político: Gramsci. Porto Alegre: L\&PM, 1981.

. Gramsci: um estudo sobre seu pensamento político. Rio de Janeiro:

Campus, 1989.

. Dualidades de poderes. São Paulo: Brasiliense, 1987.

DEMO, Pedro. Cidadania tutelada e cidadania assistida. Campinas: Autores Associados, 1995.

ESCOREL, S. Reviravolta na saúde: origem e articulação do movimento sanitário. Rio de Janeiro: Fiocruz, 1998.

FRANCO, T. B.; MERHY, E. B. Programa Saúde da Família (PSF): contradições de um programa destinado à mudança do modelo tecnoassistencial. In: CONGRESSO PAULISTA DE SAÚDE PÚBLICA, 2000, São Paulo. Anais... São Paulo: Associação Paulista de Saúde. 2000, p. 145-154.

MUCK, L. G. Formação de atores, coordenação social e estratégia política: problemas conceituais: Dados v. 40 n. 1, Rio de Janeiro 1997. Disponível em: <file://A:Dados\%20b\%20Formação\%20de\%Atores, \%20Coordenação\%20 Soci>. Acesso em: 1 jan. 2000.

GOHN, Maria da Glória. Conselhos gestores e participação sociopolítica. São Paulo: Cortez, 2003.

RODRIGUES, P. H.; KORNIS, G. E. M. Apocalipse não: o Estado do BemEstar social sobrevive à onda neoliberal. 2003. Tese (Doutorado em Saúde Coletiva) - Instituto de Medicina Social, Universidade do Estado do Rio de Janeiro, Rio de Janeiro, 2003.

SPOSATI, Aldaíza de Oliveira.; LOBO, Elza. Controle social e política de saúde. Cad. Saúde Pública. Rio de Janeiro, n. 8, p. 366-378, 1992.

STOTZ, E. N. Saúde pública e movimentos sociais em busca do controle do destino. In: VALLA, V. V.; STOTZ, E. N. (Org.). Educação, saúde e cidadania. Petrópolis: Vozes, 1994. p. 123-142. 
TORO, J. B.; WERNECK, D. N. M. Mobilização social: um modo de construir a democracia e a participação. Brasília: Ministério do Meio Ambiente, 1997.

VALLA V. V. A crise de interpretação é nossa: procurando compreender a fala das classes subalternas. Educação e Realidade, v. 21, n. 2, p. 177-190, jul./dez. 1996.

. Educação popular, saúde comunitária, apoio numa conjuntura de mobilização sobre a globalização. Cad. Saúde Pública, Rio de Janeiro, v. 15, p. 7-14, 1999. Suplemento, 27.

. Sobre participação popular: uma questão de perspectiva. Cad. Saúde Pública, Rio de Janeiro, n. 14, p. 7-18, 1998. Suplemento, 21.

VALLA. V. V.; STOTZ, E. N. Participação popular e saúde. Petrópolis: Gráfica Serrana, 1989.

WENDHANSEN, A. O. O duplo sentido do controle social: (des)caminhos da participação em saúde. Santa Catarina: Univali, 200

\section{NOTAS}

- Professor mestre no Centro Universitário Serra dos Órgãos (UNIFESO-Teresópolis) e na Faculdade Arthur Sá Earp Filho (FASE-Petrópolis); enfermeiro (Secretaria de Estado de Saúde do Rio de Janeiro). Endereço eletrônico: neipestana@gmail.com.

- Prof. Dra. Universidade Federal do Estado do Rio de Janeiro-UNIRIO. Endereço eletrônico: lilianaangel@globo.com.

- Prof. Dra. Universidade Federal do Estado do Rio de Janeiro-UNIRIO. Endereço eletrônico: fscarparo@openlink.com.br. 


\section{ABSTRACT}

Contradictions of the Manager Council of the Family Health Unit of Vargem Grande, in Teresópolis City, state of Rio de Janeiro

This paper presents a study on the contradictions of the Manager Council of Vargem Grande Family Health Unit, in Teresópolis City, state of Rio de Janeiro, concerning community health needs. The study helps understand public control policies of a Family Health Unit Manager Council, strategically based on changes of the health care model starting from the Primary Care Network. The aim was to analyze how the Council solves community deadlocks and problems, and to discuss contradictions of the decision process. It is a case study with qualitative approach. Counselors were interviewed and the Council's minutes were analyzed. Thematic analysis was used to identify problems and contradictions of the Manager Council. Data showed that deadlocks and problems are of political, economical, social and cultural nature and that they overcome the scope of the Council. The Council's attributions reveal a control practice restricted to service rationalization of the unit administration matters. The Council was not able to interfere on health politics neither on public budget destinations. So the counselors' attributions are deprived of political sense to guarantee citizenship and the conquest of social rights. The conclusion was that Vargem Grande' Manager Council is not an effective possibility of popular participation in an enlarged State public control in the Gramscian sense.

Key words: Manager council; family health; public control. 